\title{
Multi-objective Optimal Parameter Design of Nanofilters and Heat Sink Fins in Train Traction Motor Drive System
}

\author{
Jian-Long Kuo* \\ Department of Mechatronics Engineering, National Kaohsiung University of Science and Technology, \\ Kaohsiung 811, Taiwan
}

(Received December 29, 2020; accepted April 1, 2021)

Keywords: multi-objective optimal design, heat sink modules, heat dissipation, intelligent maintenance, train traction motor drive system

In this paper, the multi-objective parameter design of the heat sink modules of the converter and inverter in a train traction motor drive system was studied. The high-power insulated gate bipolar transistor (IGBT) devices embedded in converter and inverter modules usually generate considerable heat due to pulse width modulation (PWM) switching behavior. An appropriate heat dissipation system should be designed to reduce the temperature rise of the devices and to ensure their safe operation. The response surface method (RSM) was used to build a statistical model of the studied problem. The optimal design for the heat dissipation system is to minimize the objective functions of both the inlet temperature and outlet temperature of the heat sink modules. The three major control factors selected for the RSM are the mileage of nanofilter usage, the nanofilter type, and the limited current of the inverter. Since it is difficult to find an appropriate mathematical model associated with the three control factors that are based on physical principles, the optimal design of experiments (DOE) technique was used to describe the relation among the three control factors. In order to obtain the optimal inlet temperature and outlet temperature of the heat sink modules, multi-objective optimal design of the heat sink modules was addressed. The multiple performance characteristics index (MPCI) method was used to combine the two objective functions into one integrated index. To solve the nonlinear statistical model, orthogonal particle swarm optimization was used to efficiently find the optimal solution. Results showed that the obtained optimal solution provided the lowest inlet temperature and lowest outlet temperature for the heat sink modules in the train traction motor drive system. The statistical model can also be uploaded onto a cloud server to provide an effective cloud model. The optimal parameter design of the heat sink modules in the train traction motor drive system can be applied to provide effective information for an intelligent maintenance system (IMS) of the heat sink modules. The developed IMS is expected to increase the availability and reliability of nanofilters and heat sink fins using Internet of Things (IoT) and Industry 4.0 techniques.

*Corresponding author: e-mail: jlkuo@nkust.edu.tw https://doi.org/10.18494/SAM.2021.3272 


\section{Introduction}

\subsection{Cooling demand of power electronic devices}

In recent years, the cooling demand of power electronic devices has become critical due to the increasing power demand of IGBT modules. In particular, in electric trains, if the IGBT die temperature exceeds safety limits, the motor drive system of the vehicle will be unable to operate, resulting in increased maintenance costs.

IGBT modules are becoming more accepted and are increasingly used as high-power and high-voltage switching components in power electronic systems. However, IGBT technology with high speed and greater packaging density leads to higher power densities on the chips and higher operating temperatures. Higher operating temperatures, in turn, lead to an increased failure rate and reduced reliability.

As power electronic applications continue to switch higher voltages and currents in smaller component packages, the resulting increase in power density requires efficient thermal management. Sarkar and Issac described the thermal analysis of a three-phase inverter operated under a sinusoidal pulse width modulation (SPWM) technique, which used three sine waves displaced with a $120^{\circ}$ phase difference as the reference signal. ${ }^{(1)}$ They showed that thermal radiation from a heat sink played a crucial role in maintaining the junction temperature of the IGBT below a threshold value by adjusting various heat sink parameters.

Han and Jeong proposed the use of a heat $\operatorname{sink}^{(2)}$ attached to an IGBT module to dissipate heat caused by electric losses of the IGBT/diode chips and to satisfy the practical design criteria of IGBT modules. To evaluate the performance of an air-cooled heat sink, they verified the suitability of the simulation model through experimental results obtained with the developed product.

Chen et al. introduced the concept of the thermal resistance and physical structure of the IGBT module and the principle of thermal impedance tests. ${ }^{(3)}$ According to their theoretical qualitative analysis and experimental research, the junction-case steady-state thermal resistance varies as a function of the heat current, heat sink conditions, sample time, and ambient temperature. The transient thermal impedance curve and junction-case steady-state thermal resistance of a certain type of IGBT were obtained by thermal resistance test experiments. They found that the junction-case steady-state thermal resistance was a function of the heat current.

$\mathrm{Yu}$ and Webb used a computational fluid dynamics (CFD) technique to identify a cooling solution for a desktop computer that used an $80 \mathrm{~W} \mathrm{CPU} .^{(4)}$ An appropriate CPU heat sink was able to meet the CPU temperature specification. System-level design improvements were also made to provide better cooling for Accelerated Graphics Port (AGP) and Peripheral Component Interconnect (PCI) cards.

\subsection{Boiling cooling process}

To enhance boiling cooling performance, pin fins with a microporous coating have been used on the boiling plate surface. ${ }^{(5)}$ Heat rejection from the module has been achieved using two 
methods: a water-cooled cold plate and an air-cooled heat sink/fan assembly. In addition to experimental testing, an empirically based performance prediction method has also been developed. With the water-cooled cold plate and a chip temperature constraint of $100{ }^{\circ} \mathrm{C}$, the cooling module was capable of dissipating heat fluxes of 1850 and $2100 \mathrm{~kW} / \mathrm{m}^{2}$ for cold-plate water inlet temperatures of 35 and $20^{\circ} \mathrm{C}$, respectively. In addition, the total thermal resistance for the case of a $35^{\circ} \mathrm{C}$ inlet was calculated to be $0.355 \mathrm{~K} / \mathrm{W}$. The use of a microporous coating on the boiling section improved heat transfer by about $31 \%$. With an air-cooled heat sink/fan assembly and the same chip temperature constraint of $100{ }^{\circ} \mathrm{C}$, the cooling module was capable of dissipating a heat flux of $2200 \mathrm{~kW} / \mathrm{m}^{2}$ and exhibited a total thermal resistance of $0.349 \mathrm{~K} / \mathrm{W}$ at an ambient air temperature of $22^{\circ} \mathrm{C}$.

Lee presented a novel approach to optimize the pin-fin array design of an integrated liquidcooled IGBT power module. ${ }^{(5)}$ The results from his study indicated that the device junction temperatures were not only reduced in magnitude but also equalized. In addition, the maximum power dissipation of the module was enhanced. Lee also compared the direct pool boiling and indirect cold-plate liquid-cooling techniques.

Yun et al. analyzed the static and dynamic thermal behaviors of an IGBT module system mounted on a water-cooled heat sink. ${ }^{(6)}$ This approach enabled a system designer to simultaneously couple a thermal prediction with a circuit simulator to analyze the electrothermal behavior of an IGBT module system. Lee et al. described the development of a watercooled heat $\operatorname{sink}^{(7)}$ and provided a reliable thermal performance for a high-power IGBT inverter. They made a prototype of the resultant design and tested the experimental setup to confirm the validity of the design.

Moores and Joshi presented the thermal analysis and experimental performance assessment of an aluminum silicon carbide (AlSiC) metal matrix composite (MMC) base plate with integral cooling fins. ${ }^{(8)}$ By attaching a pin-fin base plate to an open-chambered flow-through heat sink, the mechanical interface between the base plate and cooling medium was eliminated.

Kim et al. investigated a liquid-cooled module as a means of cooling electronic devices using boiling and condensation heat transfer. ${ }^{(9)}$ The liquid-cooled module comprised a boiling plate, a spacer, and a condenser plate and used FC-72 as the working fluid. The size of the module was $101 \mathrm{~mm} \times 108 \mathrm{~mm} \times 18 \mathrm{~mm}$ and the chip size (heat source) used was $10 \mathrm{~mm} \times 10 \mathrm{~mm}$.

Salem et al. compared the thermal performance for the operation of a MOSFET on a watercooled pole-arrayed heat sink versus one operating on a novel water-cooled microchannel heat sink. ${ }^{(10)}$ They presented an innovative technique for determining the thermal capacitance modeling parameters for heat sinks from experimental data. Maveety and Jung presented a comparative investigation between experiments and numerical simulations for the impingement of a turbulent air flow on a square pin-fin heat sink. ${ }^{(1)}$ They conducted some experiments using an aluminum heat sink subjected to a uniform heat flux by using a silicon test chip. The predicted thermal resistance of the heat sink was in good agreement with those obtained from experiments.

Morozumi et al. developed a directly-liquid-cooled IGBT module that simultaneously enabled the downsizing of a power control unit for an HEV system and had high reliability. ${ }^{(12)}$ This module eliminated the need for thermal grease by unifying a ceramic substrate and a heat 
sink. This module reduced thermal resistance by $30 \%$ compared with that of a conventional indirect-liquid-cooled type.

\subsection{Analytic methodology}

Chiang presented an effective method for predicting and optimizing the cooling performance of a parallel plane fin (PPF) heat sink module based on the Taguchi method. ${ }^{(13)}$ He performed numerical simulative analyses of a PPF heat sink module to understand the effect of its related modeling parameters. The design parameters evaluated were the outline design of the heat sink module and the wind capacity of the fan, and the thermal resistance of this module was considered as the performance characteristic.

Cheng et al. demonstrated the applications of CFD simulation and the response surface method (RSM). ${ }^{(14)}$ They analyzed the thermal performance of a high input/output, indirectliquid-cooled multichip module with seven chips, which is applied in a supercomputer.

A series of similar experiments and corresponding CFD simulations were first conducted to evaluate the validity of the CFD simulation method and iteratively determine the interfacial thermal resistance of thermal grease. Then, a three-dimensional CFD model was established to investigate the heat transfer and fluid flow of the multichip module. By using the CFD model, the individual effects of control factors such as the thermal conductivity of the thermal interface material and thermal grease, the thickness of the chips, the space between the chips, the solder bump pattern, the solder ball pattern, the flow velocity, and the liquid inlet temperature on the thermal performance of the module were experimentally studied. Three significant control factors were selected to establish a response surface model of the maximum temperature of the module with the central composite design based on the RSM and the analysis of variance.

\subsection{Sensor description}

In the heat sink fins of our work, five temperature sensors are used to detect the real-time temperature variation. Five locations are selected to place the temperature sensors: the U phase converter, the $\mathrm{V}$ phase converter in the rectifier part, the $\mathrm{U}$ phase inverter, the $\mathrm{V}$ phase inverter, and the $\mathrm{W}$ phase inverter in the inverter part.

To obtain an integrated temperature for heat sink fins, the five temperature values obtained by the sensors are averaged. Also, since the real-time temperature rapidly varies, the PC-based analysis system uses a low-pass filter to convert the rapidly varying data into slowly changing data.

Three factors are defined in this paper. Factor A is the mileage of nanofilter usage $(\mathrm{km})$, for which a mileage measurement system is required. A speed/position sensor is embedded in the motor system to detect the mileage value in high-speed trains. Factor B is the nanofilter type $(\mathrm{kPa})$. The nanofilter type is related to the material selected to determine the appropriate $\mathrm{kPa}$ value for the nanofilter module. Factor $\mathrm{C}$ is the inverter limited current (A). The sensors detecting the inverter current are embedded in the motor drive system. $\mathrm{U}$ phase and $\mathrm{V}$ phase current values are sensed and controlled. The limited current command is set up in the motor 
control system. Current control loops are designed to keep the high-speed train operating under a constant current.

\subsection{Research purpose}

Some operational environmental factors cannot be analyzed by CFD software. Different railway systems in different countries have different environment conditions. The dust in different countries might affect the selection of the nanofilter of heat sink modules. The nanofilter type is an essential control factor. Also, the mileage of filter usage should be considered to determine the appropriate nanofilter replacement time.

In this study, to ensure the safe operation of the train traction motor drive system, effective heat sink modules and nanofilters are required. Effective nanofilters keep the air flow clean in heat sink modules. The dust accumulated on nanofilters might affect the air flow, causing the temperature to rise quickly. However, too frequent filter replacement might increase the maintenance cost.

To resolve the trade-off between cost and safety, an optimal design is required to determine the appropriate nanofilter type and replacement time. This makes it necessary to develop a statistical model to describe and analyze the problem. The optimal solution can then be derived using the RSM.

In this paper, multivariate data analysis is used to analyze all types of data. The associated analysis is a new technique that is useful in today's world of analytics. Multivariate data analysis provides an application-oriented method for multivariate analysis for the studied problem. By performing statistical research into cloud-based algorithms, we explain how to understand and make use of the proposed specific statistical technique in the cloud computing field.

\section{Heat Sink Fins and Nanofilters in Traction Motor Drive System}

\subsection{System overview}

An overall view of the studied traction motor drive system is shown in Fig. 1. The converter and inverter testing systems are shown. The heat dissipation system is required to remove the heat generated by the IGBT devices from the heat sink fins. The heat sink fin structure is arranged to dissipate the heat of the IGBT devices from the heat sink fins as shown in Fig. 2.

\subsection{Boiling cooling process and temperature variation}

As shown in Fig. 3, a refrigerant is arranged at the bottom of the pool boiling tank to remove the heat from the IGBT device surface. The boiling cooling method is used to remove the heat. The boiling refrigerant flows from the bottom to the top. Heat transfer occurs from the refrigerant to the heat pipe/heat sink fins. Air cooling occurs at the top to remove heat from the heat pipe/heat sink fins to the outside. Then, the boiling refrigerant is condensed again and flows back to the bottom. The refrigerant is once again recycled in its boiling cooling process. 


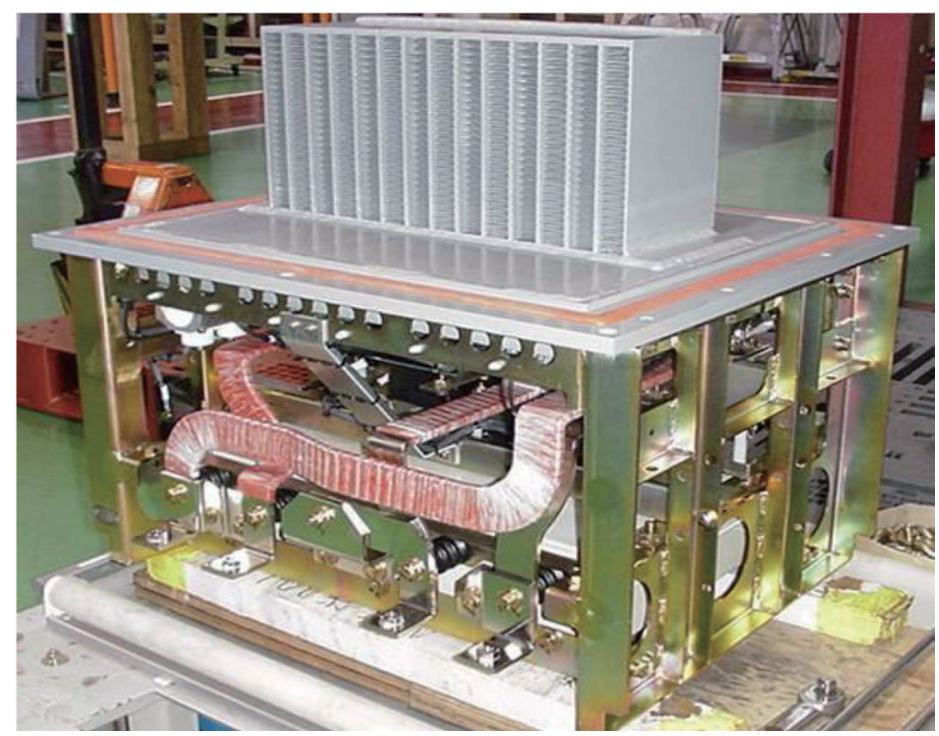

Fig. 1. (Color online) Converter and inverter modules in the traction motor drive system.

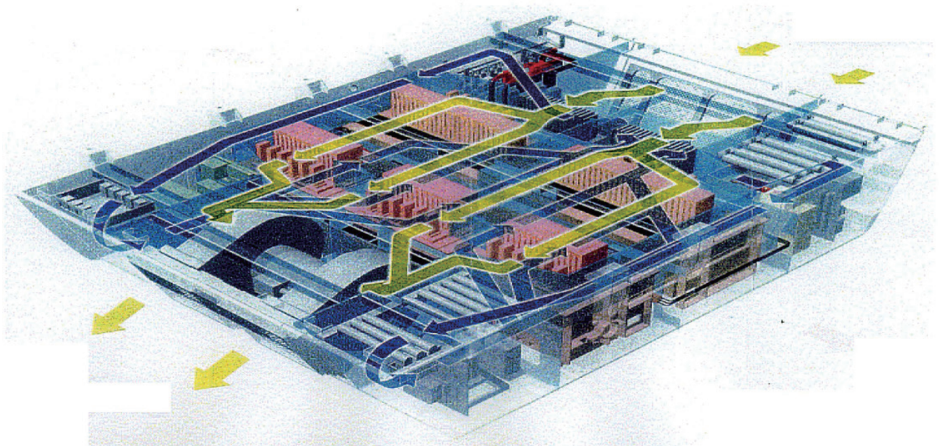

Fig. 2. (Color online) Heat sink module of traction motor drive system.

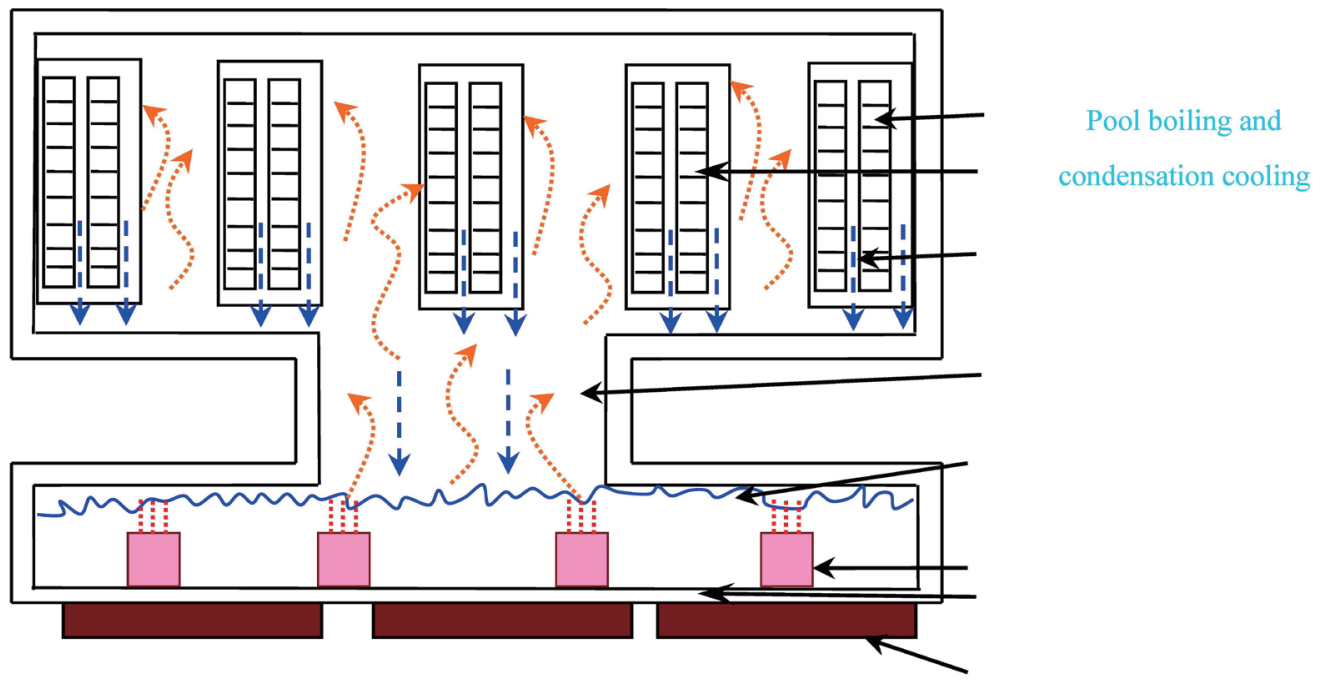

Fig. 3. (Color online) Pool boiling and condensation cooling in heat dissipation system. 
The junction temperature variables of the IGBTs/diodes are defined in Fig. 4. When the IGBT devices perform PWM switching, heat dissipation occurs due to switching loss from the equivalent resistances of the IGBTs/diodes.

As shown in Fig. 5(a), a large current occurs when the traction motor drive system operates at a high speed. The threshold between the constant-current and constant-power regions is at about $100 \mathrm{~km} / \mathrm{h}$ : the constant-current region is below $100 \mathrm{~km} / \mathrm{h}$ and the constant-power region is above $100 \mathrm{~km} / \mathrm{h}$.

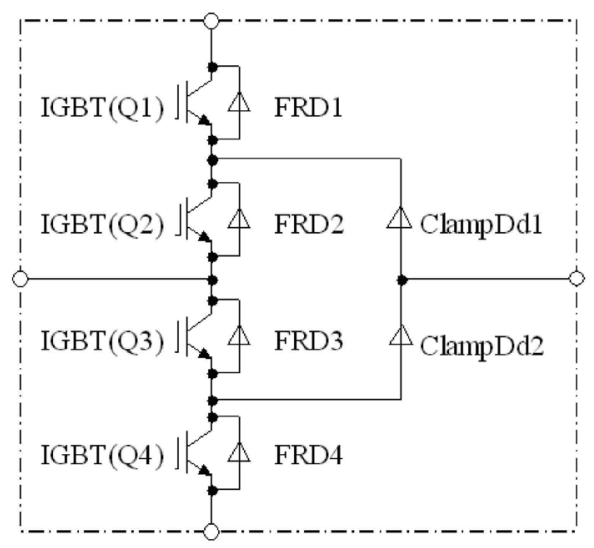

Symmetry

$\mathrm{T} j \operatorname{IGBT}(\mathrm{Q} 1)=\mathrm{T} j \operatorname{IGBT}(\mathrm{Q} 4)$

$\mathrm{T} j \_$IGB T(Q2) $=\mathrm{T} j \__{-} \mathrm{IGBT}(\mathrm{Q} 3)$

$\mathrm{T} j \mathrm{FRD} 1=\mathrm{T} j \mathrm{FRD} 4$

$\mathrm{T} j \_$FRD $2=\mathrm{T} j \_$FRD 3

$\mathrm{T} j \_$ClampDd $1=\mathrm{T} j \_$ClampDd 2

Abbreviations

T $j$ : Junction Temperature

IGBT: Insulated Gate Bipolar

Transistor

FRD: Flywheel Diode

ClampDd: Clamp Diode

(a)

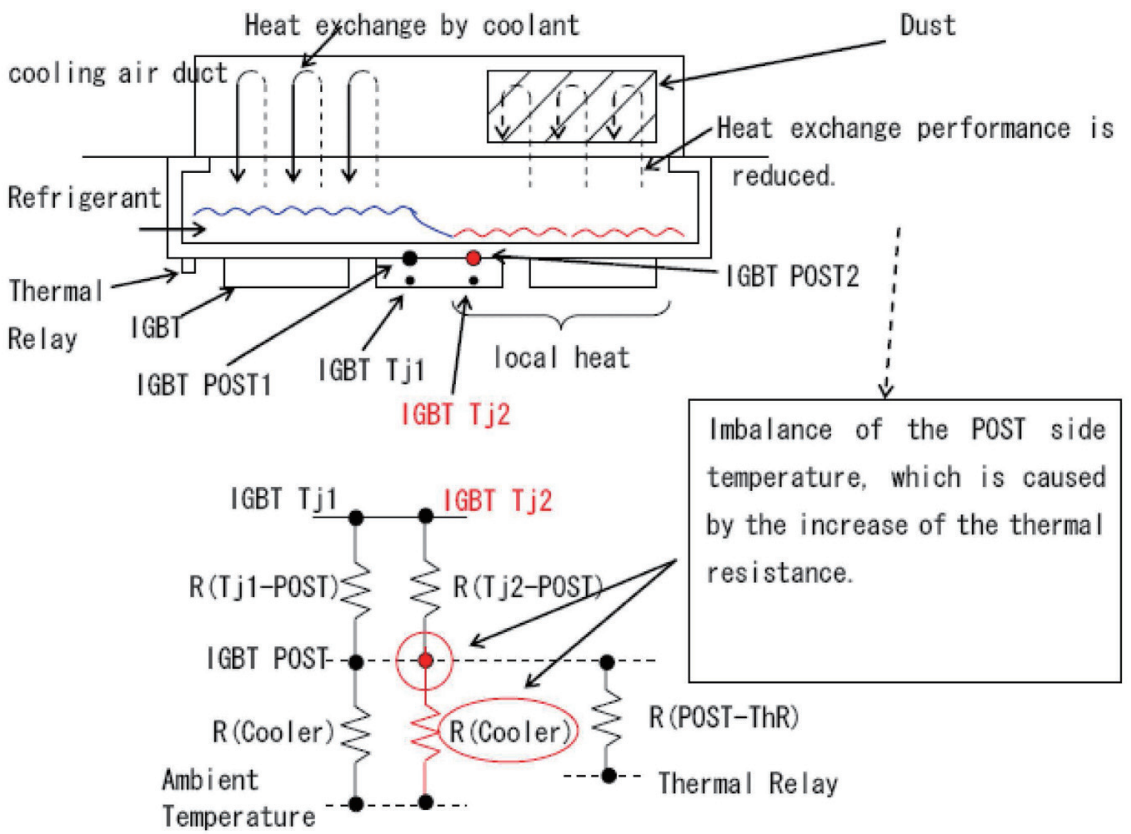

(b)

Fig. 4. (Color online) Junction temperature definition of converter/inverter circuits. 


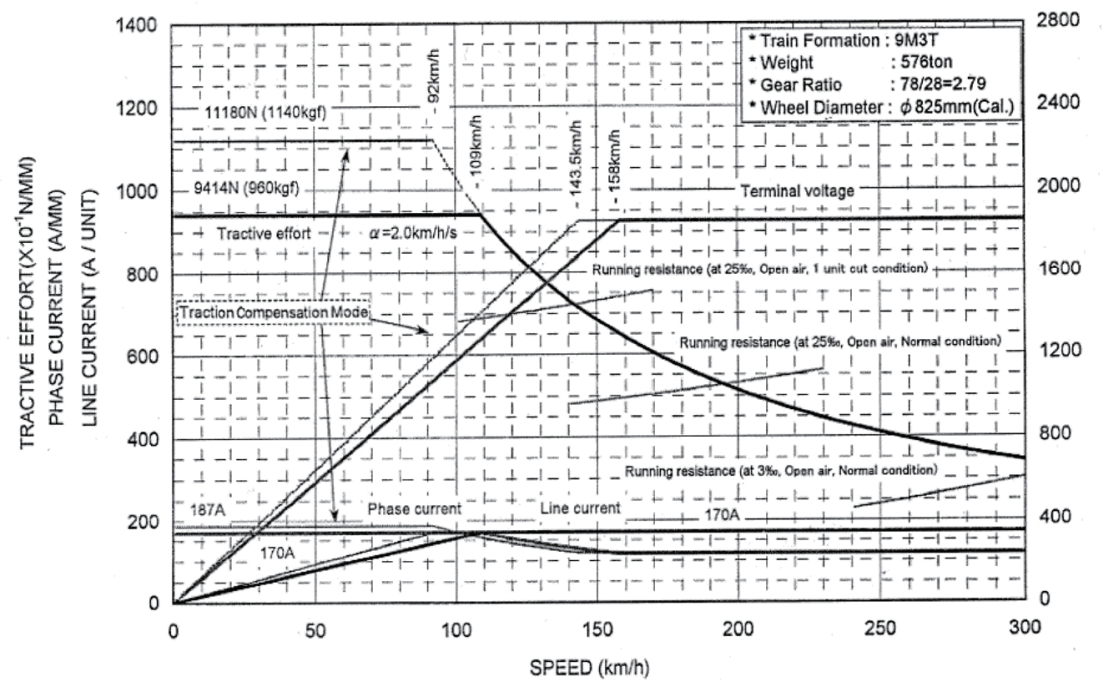

(a)

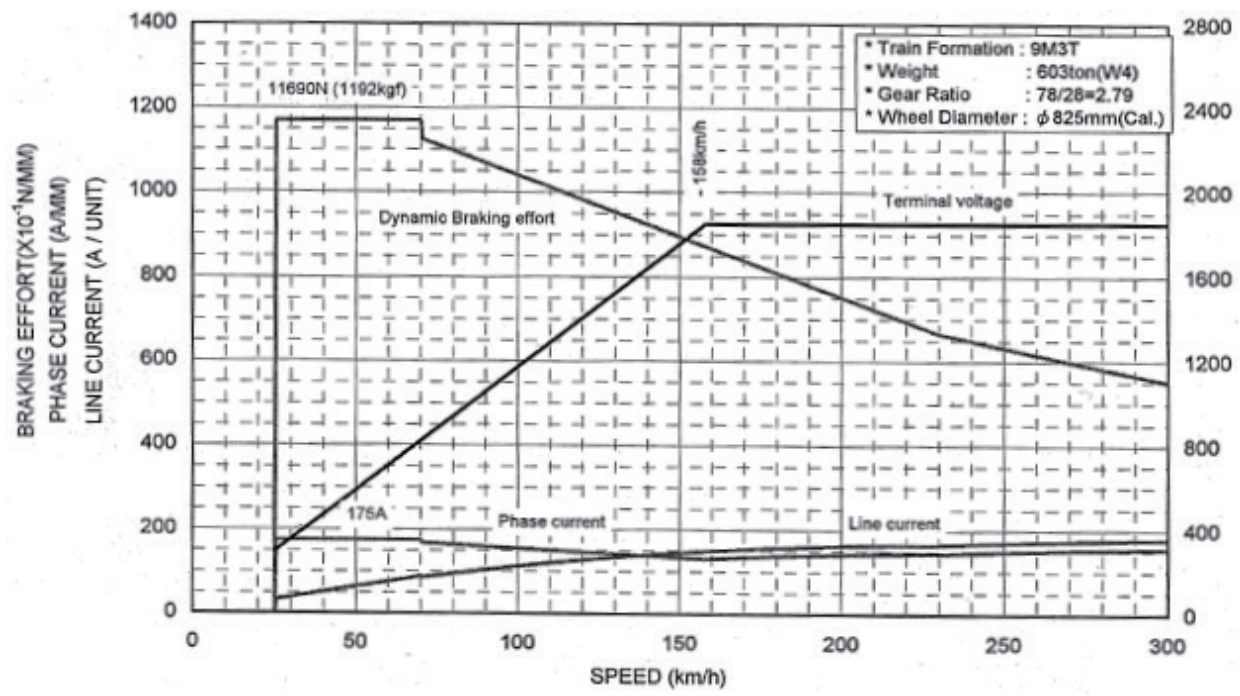

(b)

Fig. 5. Operational characteristics of traction motor drive system. (a) Current versus speed characteristics of traction motor drive system. (b) Braking characteristics of traction motor drive system.

The braking characteristics of the traction motor drive system are shown in Fig. 5(b). The constant-current region is below $75 \mathrm{~km} / \mathrm{h}$ and the constant-power region is above $75 \mathrm{~km} / \mathrm{h}$.

A comparison between the junction temperatures of a stopping train and a nonstop train is shown in Table 1 . The temperature of the inverter module is roughly $95.3^{\circ} \mathrm{C}$ and the temperature of the converter module is roughly $101.3^{\circ} \mathrm{C}$. The temperature variation during the stopping train operation is shown in Fig. 6. The temperature varies from 50 to $95.3{ }^{\circ} \mathrm{C}$. The temperature variation during nonstop train operation is shown in Fig. 7. The temperature varies from 70 to $101.3^{\circ} \mathrm{C}$. A large transient current occurs when the train starts and stops. 
Table 1

Junction temperature comparison of IGBT modules.

\begin{tabular}{llccccc}
\hline \multirow{2}{*}{ Case } & Operation type & Weight & \multirow{2}{*}{$\mathrm{M} / \mathrm{T}$ set } & \multicolumn{3}{c}{ Junction temperature } \\
\cline { 5 - 7 } Case 1 & Stopping train & W4 & $8 \mathrm{M} 4 \mathrm{~T}$ & $95.3^{\circ} \mathrm{C}$ & Converter & Figure \\
Case 2 & Nonstop train & W4 & $8 \mathrm{M} 4 \mathrm{~T}$ & $95.3^{\circ} \mathrm{C}$ & $101.3^{\circ} \mathrm{C}$ & Fig. 6 \\
\hline
\end{tabular}

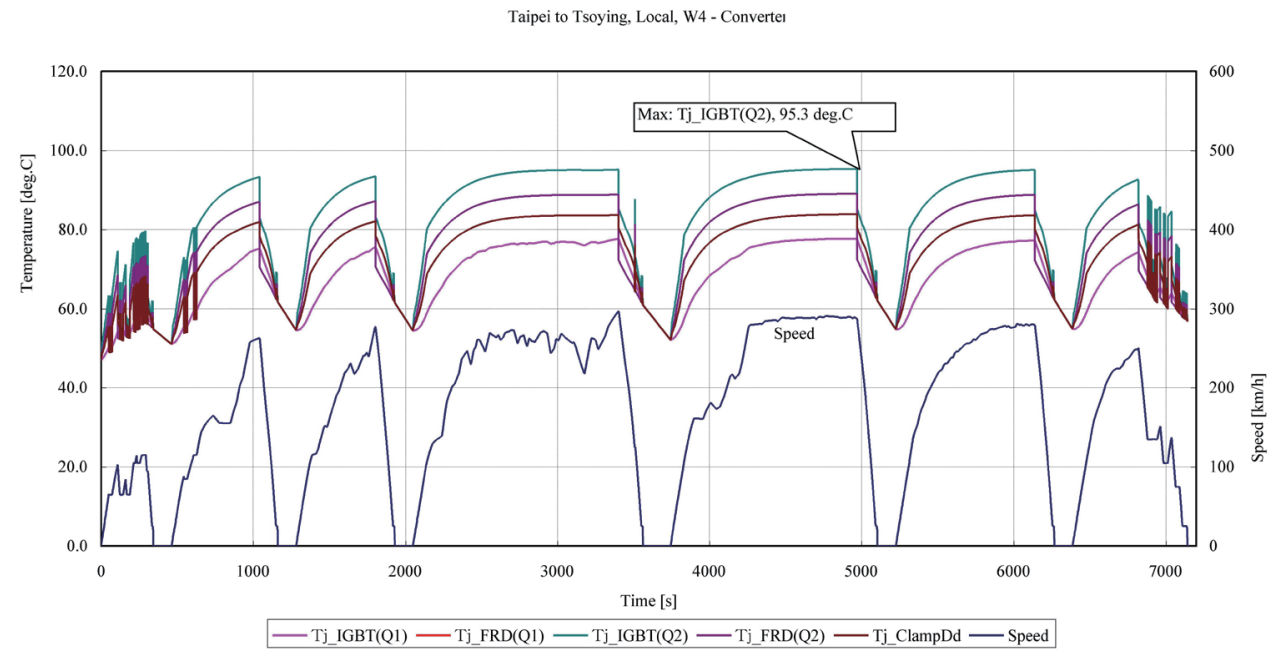

Fig. 6. (Color online) Temperature waveforms during operation (stopping train operation).

Taipei to Tsoying, Non-stop, W4 - Inverter

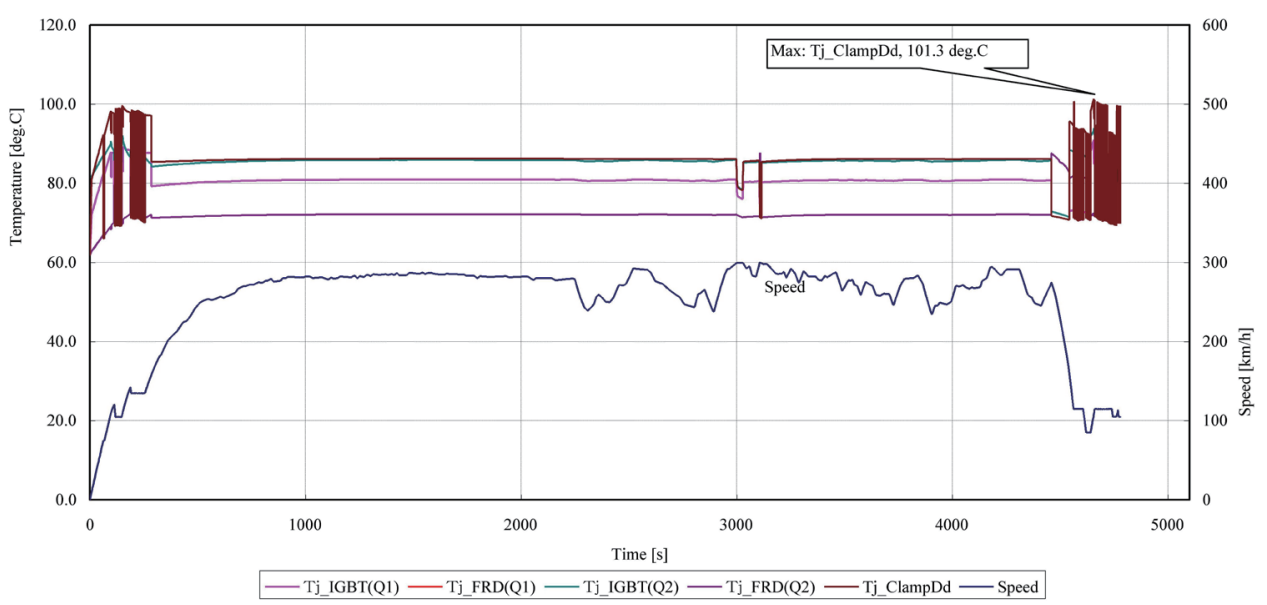

Fig. 7. (Color online) Temperature waveforms during operation (nonstop train operation).

\subsection{Heat sink fins and nanofilters}

The left of Fig. 8 shows a normal case with little dust on the nanofilter. When there is dust on the nanofilter (right of Fig. 8), the junction temperature and thermal resistance increase. When the operation mileage of the train increases, dust accumulates on the surface of the heat sink fins, slowing the air flow and increasing the junction temperature and thermal resistance. 

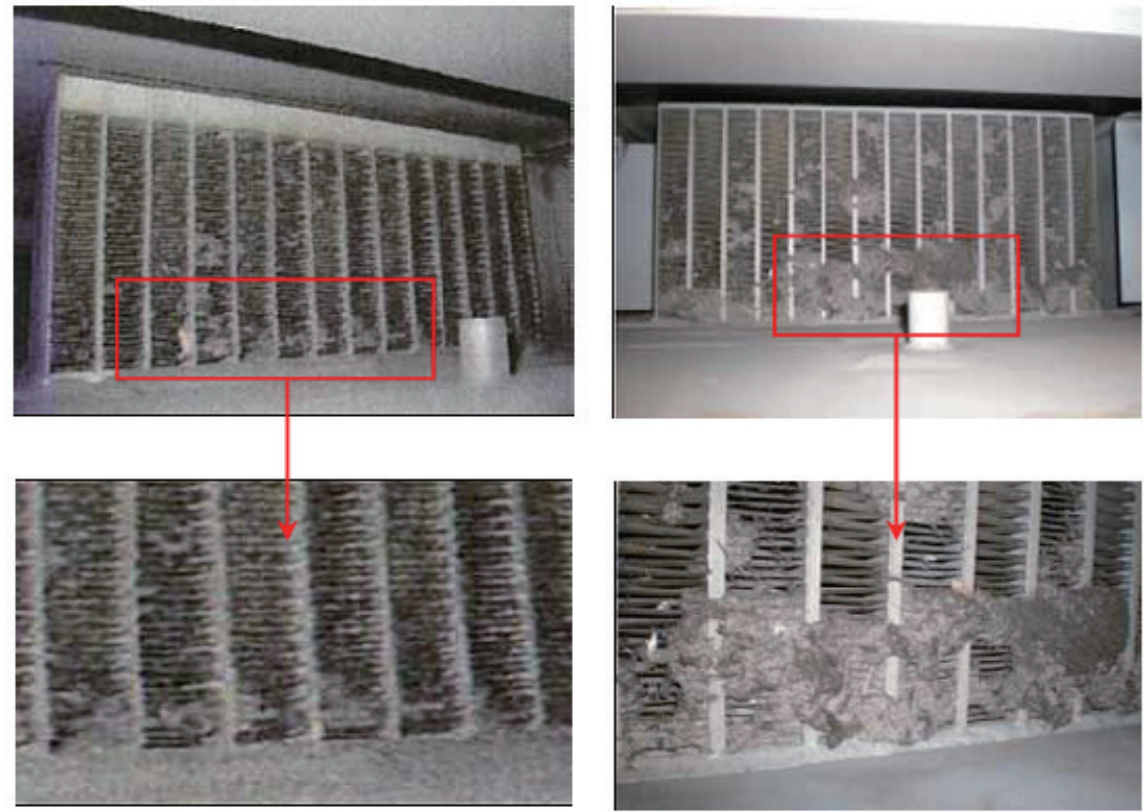

Fig. 8. (Color online) Dust accumulation on heat sink fin.

Table 2

Case studies for testing junction temperatures of IGBT modules.

\begin{tabular}{lc}
\hline & Condition \\
\hline Case 1 & Normal cooling \\
Case 2 & Dust covers $1 / 4$ of fin surface area \\
Case 3 & Dust covers $1 / 3$ of fin surface area \\
Case 4 & Dust covers $1 / 2$ of fin surface area \\
Case 5 & Dust covers $2 / 3$ of fin surface area \\
\hline
\end{tabular}

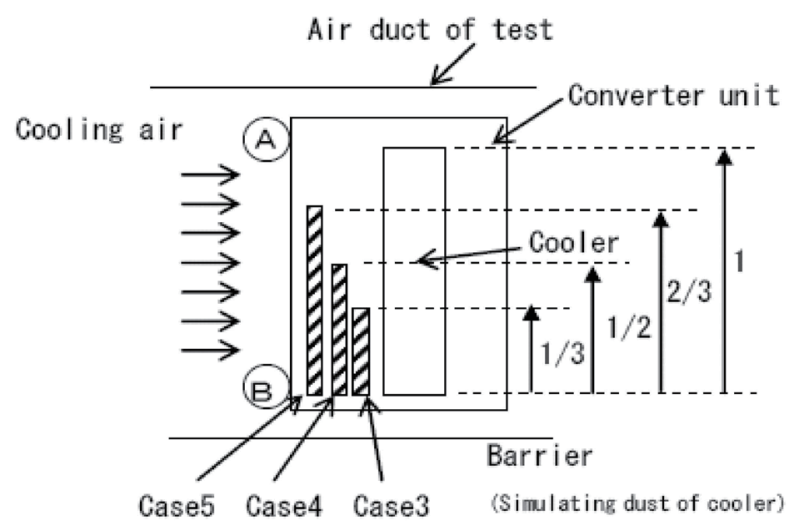

Fig. 9. Thermal model of heat dissipation system for wind tunnel tests.

To determine the effect on dust on the nanofilter, five wind tunnel tests are performed to compare the temperature variation caused by the effect of dust. The results are shown in Table 2 and Fig. 9. Case 1 is the normal case without dust, and in Cases $2-5$, dust covers $1 / 4,1 / 3,1 / 2$, and $2 / 3$ of the fin surface area, respectively. 
In Fig. 10, Cases 1 and 2 are compared. Case 2 exhibits a higher temperature than Case 1. In Fig. 11, Cases 1, 3, 4, and 5 are compared. Cases 4 and 5 exhibit higher temperatures than Cases 1 and 3.

Figure 12 shows the waveform when the limited operating current is switched from a peak value of 1500 to $2000 \mathrm{~A}$, and Fig. 13 shows the waveform when the limited operating current is switched from 1500 A to the stop mode. If the junction temperature is too high, the IGBTs/ diodes are seriously burnt and burst, as shown in Fig. 14.

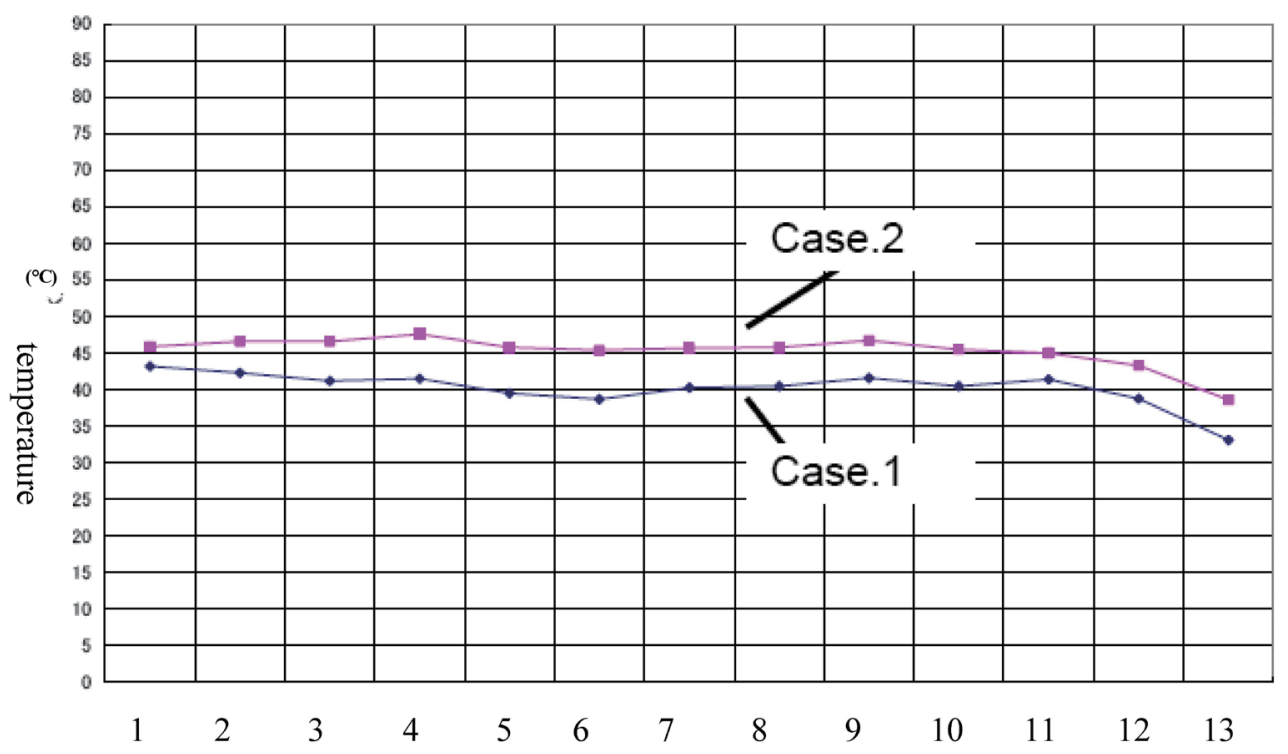

Fig. 10. (Color online) Results of wind tunnel tests of Cases 1 and 2.

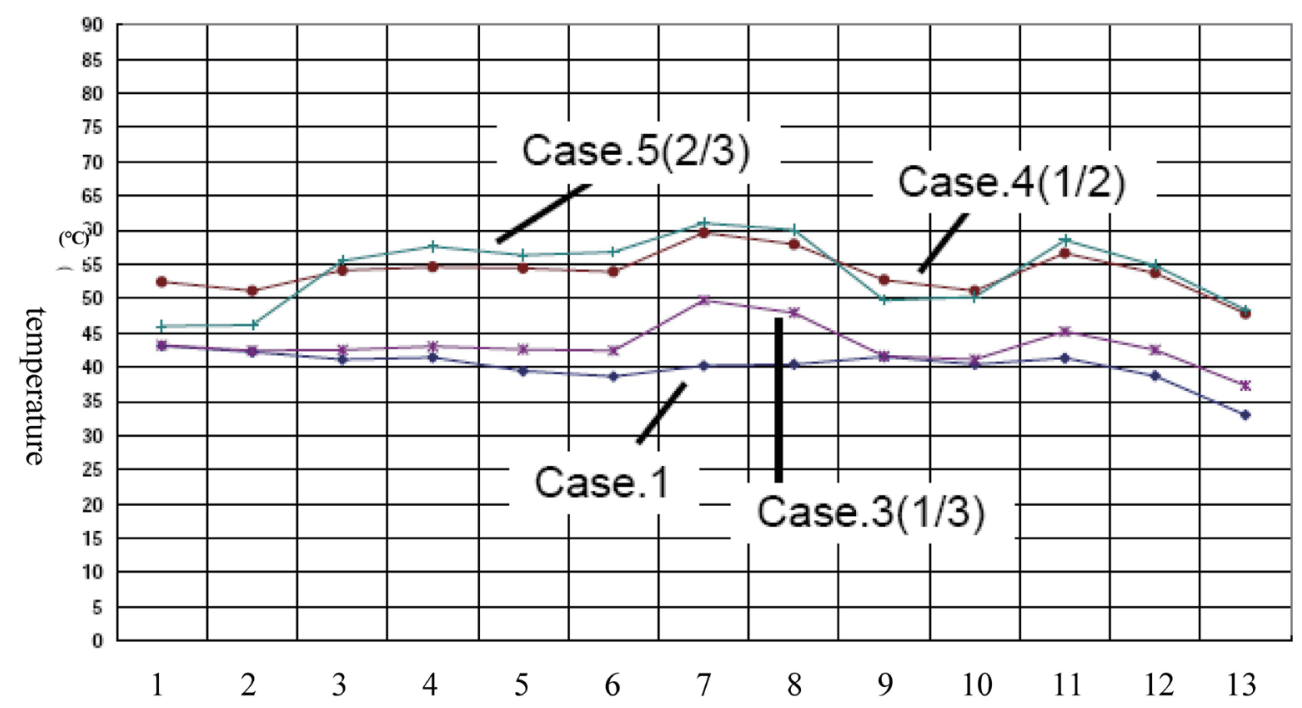

Fig. 11. (Color online) Results of wind tunnel tests of Cases 1, 3, 4, and 5. 


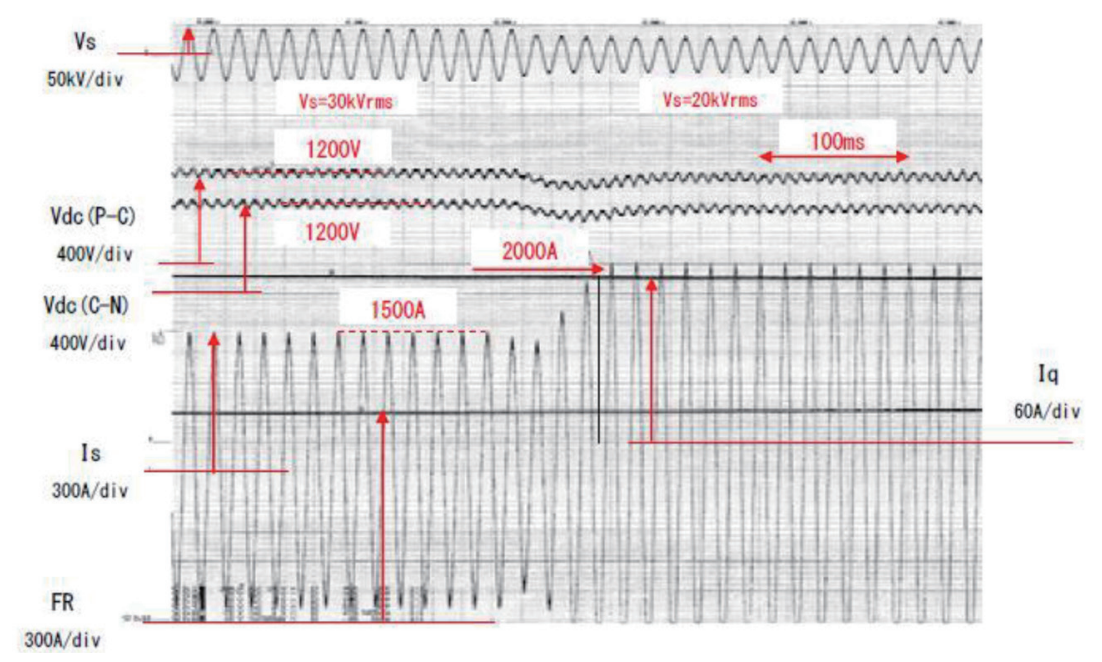

Fig. 12. (Color online) Measured waveform when limited current is switched from 1500 to $2000 \mathrm{~A}$.

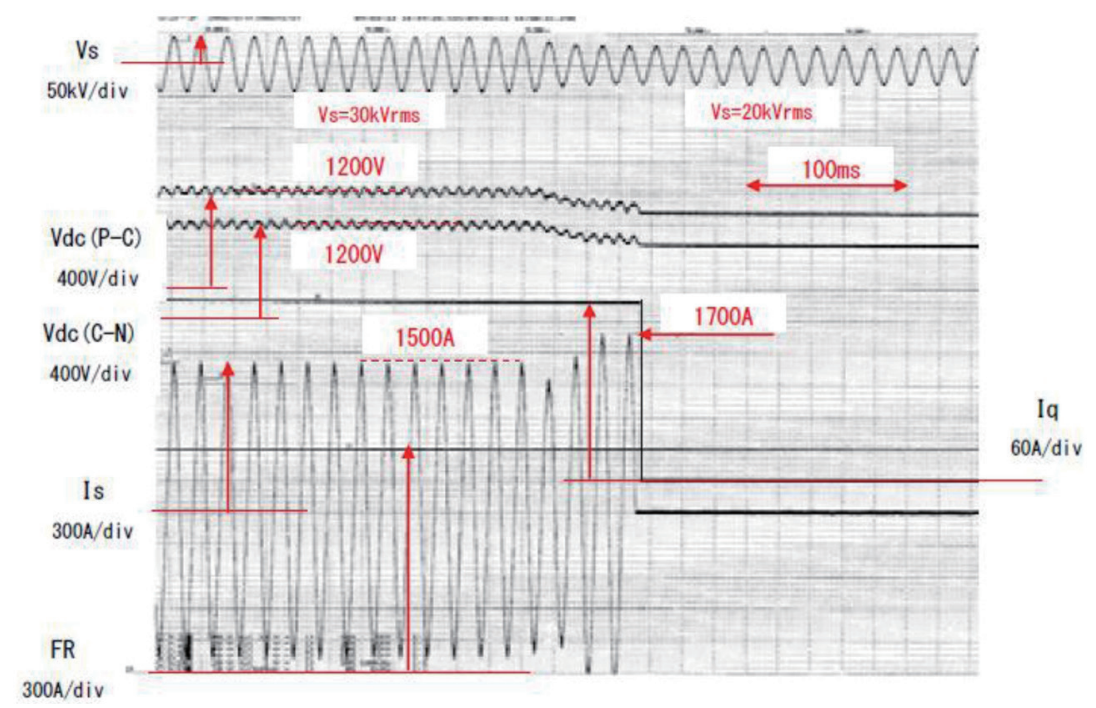

Fig. 13. (Color online) Measured waveform when limited current is switched from 1500 A to stop mode.

\section{Material Selection and Sensor Arrangement}

A series of experimental runs based on the RSM were performed to obtain the effective relation between the three studied control factors, where the inlet and outlet temperatures were recorded. Three cabins of a high-speed train were selected for the experimental testing runs. The three types of filter in Table 3 were installed in the heat sink modules of the three cabins.

The overall experimental setup is shown in Figs. 15-17. As shown in Fig. 18, two temperature recorders are used to measure the temperature of the power devices and heat sink fins. The inlet temperature recorder is located near the heat dissipation base plate of the power IGBT devices. 


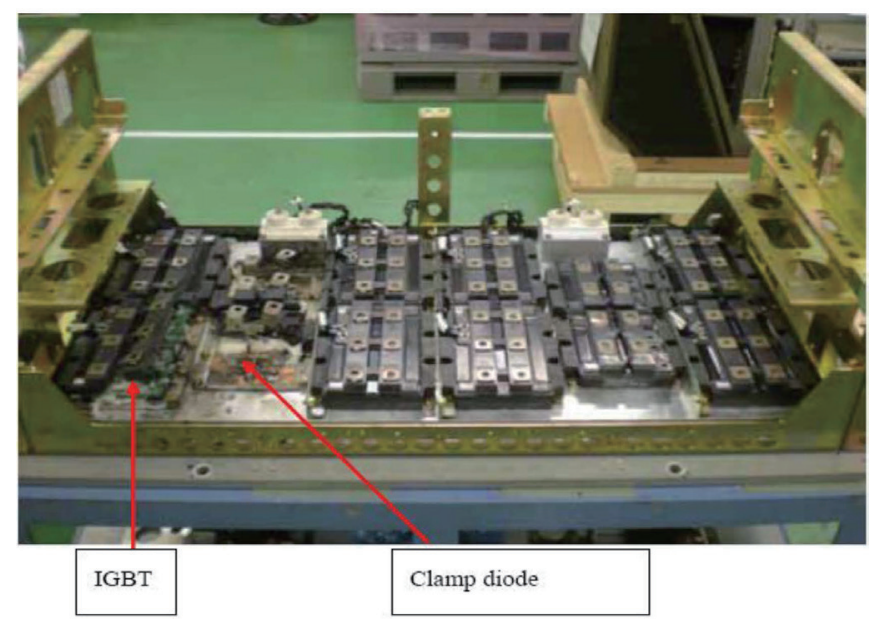

Fig. 14. (Color online) Burnt and burst IGBT and diode power devices.

Table 3

Specifications of inlet filters used in experimental runs.

\begin{tabular}{lcc}
\hline Cabin location & Filter material & Specification \\
\hline Cabin 6 & 40-mesh nanofilter & $1.6 \mathrm{kPa}$ \\
Cabin 7 & nanofilter & $0.9 \mathrm{kPa}$ \\
Cabin 8 & 25-mesh nanofilter & $2.3 \mathrm{kPa}$ \\
\hline
\end{tabular}

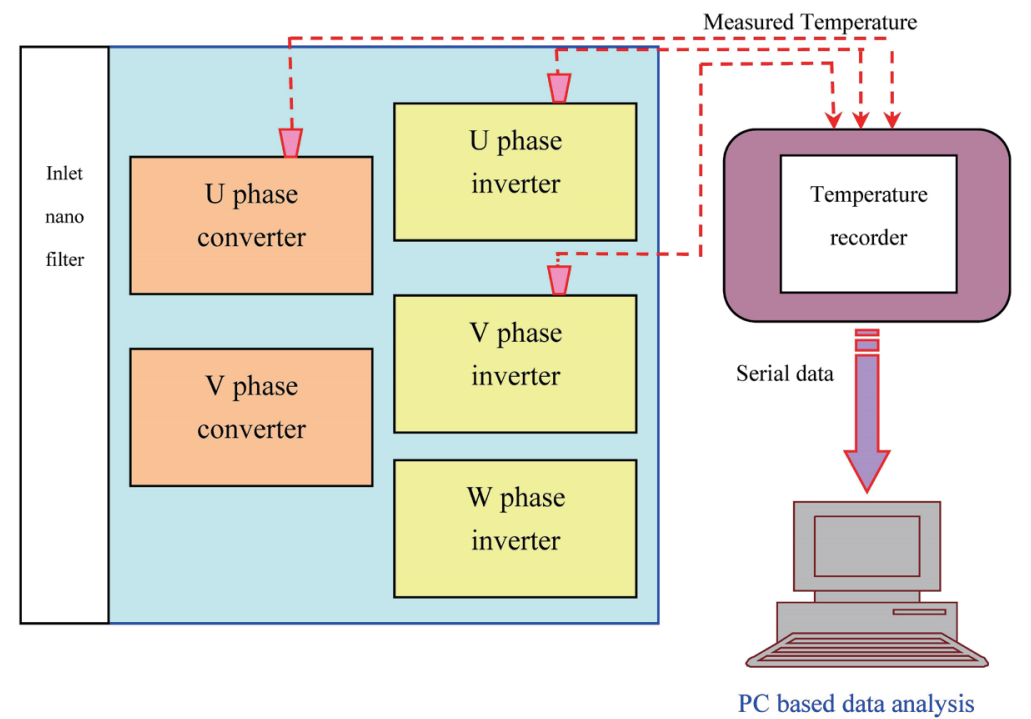

Fig. 15. (Color online) Experimental setup with temperature recording system.

The outlet temperature recorder is located near the heat sink fins. The data obtained from the two temperature recording devices are used to obtain a statistical model of the temperature associated with the three control factors. Because the three control factors are inherently empirical factors, it is difficult to derive an appropriate mathematical model using the principles of physics. 


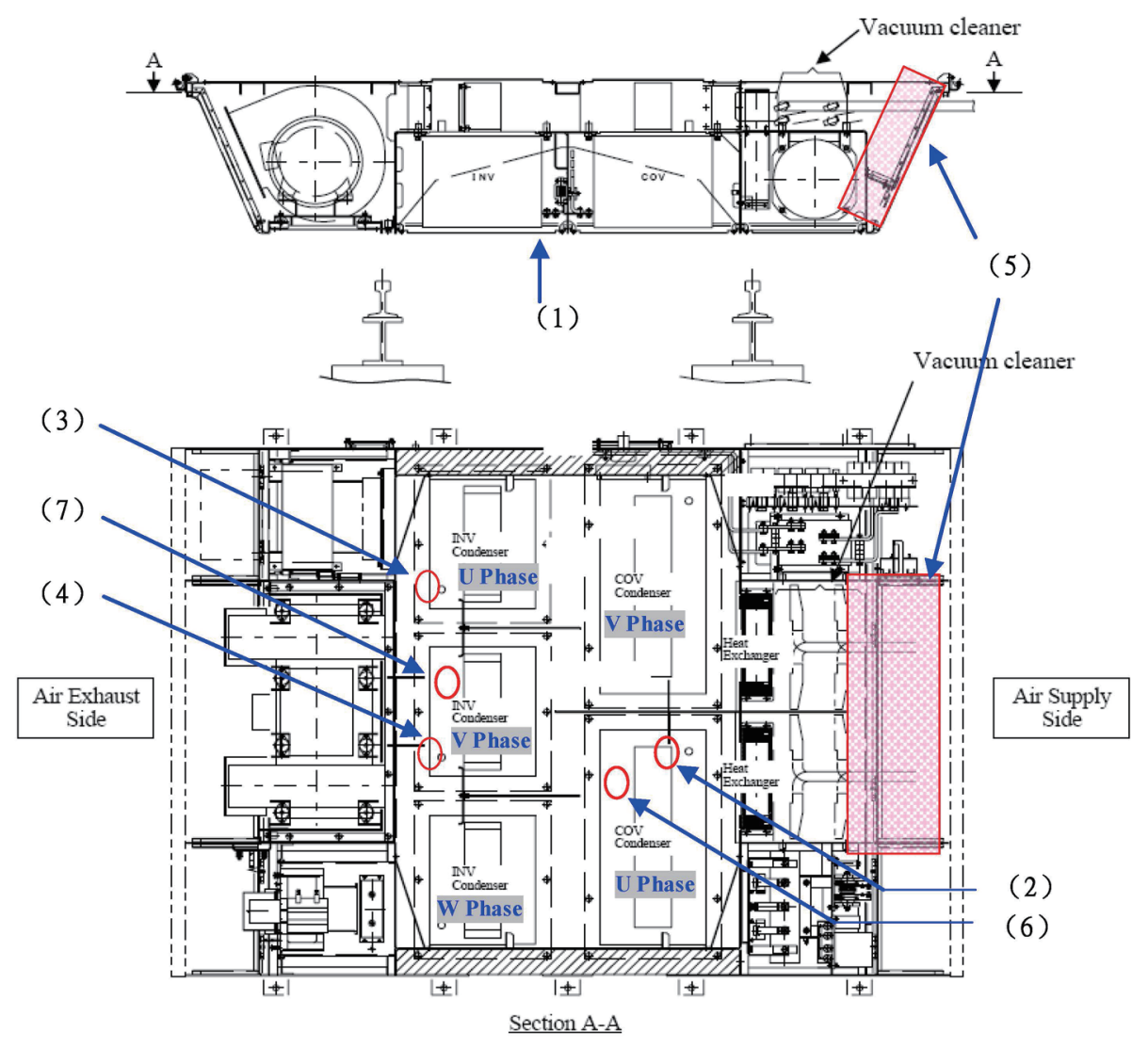

Fig. 16. (Color online) Nanofilter and vacuum cleaner arrangement of the heat sink modules.

\section{TR-0106 TPE resin-Shielded Sensor}

Cable Length: $0.6 \mathrm{~m}$ Thermal-Constant Time :

In the air : Approx. $75 \mathrm{Sec}$.

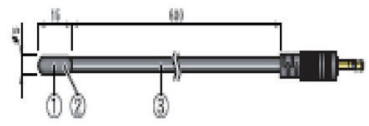

Fig. 17. T\&D-TR0106 temperature sensor.

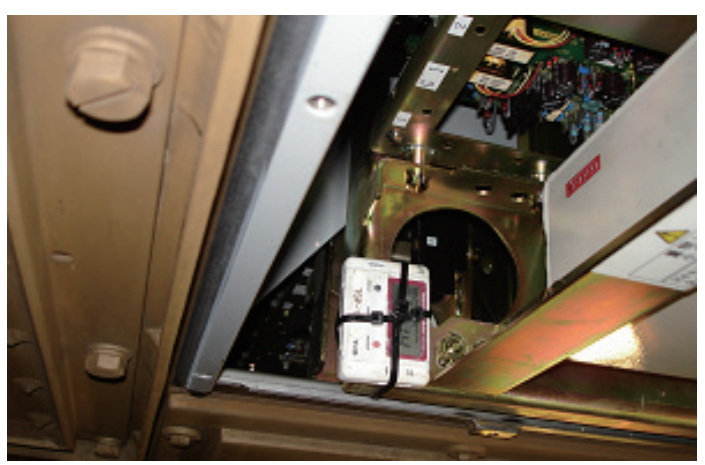

Fig. 18. (Color online) T\&D-TSP-13 temperature recorder.

The temperature recorders in Fig. 18 are installed in the heat sink modules of train cabins 6, 7 , and 8 . The three types of filter are installed in train cabins 6,7 , and 8 to maintain the same testing environmental conditions. The obtained optimal solution can provide the optimal nanofilter type and nanofilter replacement time to maintain the good condition of the nanofilter in Fig. 19.

The three types of nanofilter material in Table 3 are adopted to assess the performance of the nanofilter. In train cabin 7 , two layer 25 -mesh nanofilters with a stainless middle mezzanine 
layer nanofilter are installed, as shown in Fig. 20. In cabin 8, the middle mezzanine layer is changed from a stainless nanofilter to a synthetic fiber nanofilter, as shown in Fig. 21. In cabin 6 , 40-mesh nanofilters are added, as shown in Fig. 22.

\section{Statistical Modeling Based on RSM}

\subsection{Fuzzy inference using MPCI in statistical model}

In this paper, a statistical modeling technique based on the RSM is used. ${ }^{(15)}$ The inlet temperature and outlet temperature of the heat sink modules are selected as two objective functions for study. In the design of the nanofilter and heat sink fins, control factors possibly affecting the inlet/outlet temperature are selected to formulate a statistical model.

Three control factors are studied: the mileage of nanofilter usage, the nanofilter type, and the inverter limited current. Case 1 is used to study the problem of minimizing the inlet temperature. Case 2 is used to study the problem of minimizing the outlet temperature. Case 3 is used to study the problem of minimizing both the inlet and outlet temperatures using the MPCI method. The levels of the three control factors are defined in Table 4.

The measured inlet/outlet temperature recorded by the temperature recorder is defined as $T(i)$. The values listed in the RSM are $y_{i}=1 / T(i)$. In other words, the minimization problem is converted into a maximization problem. Case 3 is mainly focused on in this paper; Cases 1 and 2

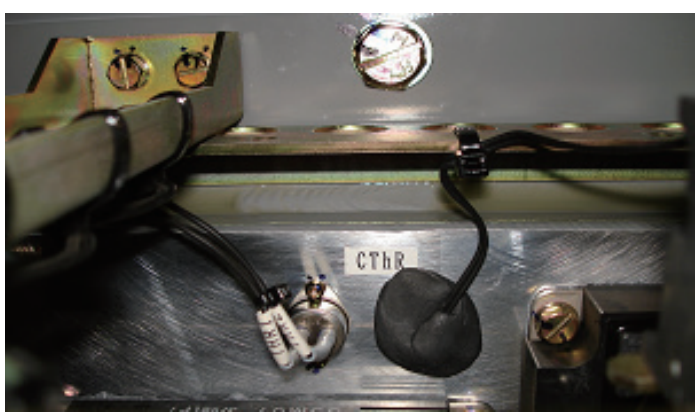

Fig. 19. (Color online) Nanofilter structure of heat sink modules.

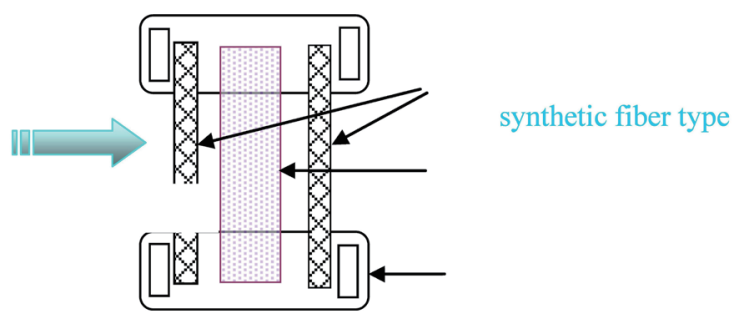

Fig. 21. (Color online) 25-mesh nanofilter arrangement in Cabin 8.

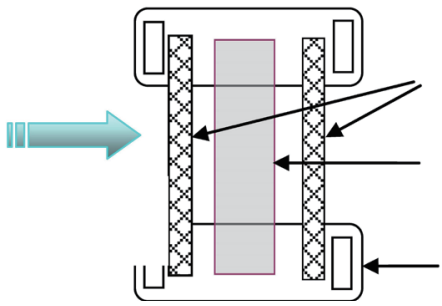

stainless middle mezzanine layer

Fig. 20. (Color online) 25-mesh nanofilter arrangement in Cabin 7.

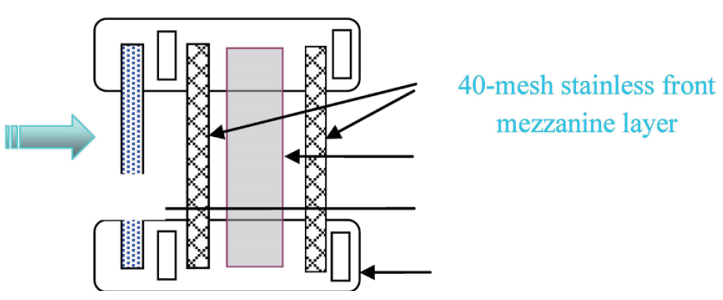

Fig. 22. (Color online) 40-mesh nanofilter arrangement in Cabin 6. 
Table 4

Level definitions in RSM.

\begin{tabular}{lccc}
\hline Factor & \multicolumn{3}{c}{ Level definition } \\
\hline Factor A & $\mathbf{- 1}$ & $\mathbf{0}$ & $\mathbf{1}$ \\
(mileage of nanofilter usage, $\mathrm{km})$ & 120000 & 90000 & 60000 \\
Factor B & $\mathbf{- 1}$ & $\mathbf{0}$ & $\mathbf{1}$ \\
(nanofilter type, $\mathrm{kPa}$ ) & 2.3 & 1.6 & 0.9 \\
Factor C & $\mathbf{- 1}$ & $\mathbf{0}$ & $\mathbf{1}$ \\
(inverter limited current, A) & 2000 & 1850 & 1700 \\
\hline
\end{tabular}

are similar and are omitted due to space limitations. Fuzzy inference is required to integrate the two sets of measured data in Cases 1 and 2 into a single compact index in Case 3. The membership functions of the measured data in Cases 1 and 2 are first defined. ${ }^{(16-18)}$

\subsection{MPCI values}

The derived final fuzzy MPCI values in Case 3 are listed in Table 5 and compared with those in Cases 1 and 2. In order to build the statistical model of the RSM, 16 experimental runs with four central-point experimental runs are performed, as listed in Table 5. ${ }^{(19,20)}$

There are a total of 20 experimental runs in the RSM. Sixteen experimental runs (Runs 1-16) are used in the combinational table and four experimental runs (Runs 17-20) are central-point experiments.

\section{Response Surface Experimental Results}

The average value in the four central-point experiments is

$$
\bar{p}_{C}=(0.261394+0.229883+0.246822+0.262494) / 4=0.250148 .
$$

The average value in the 16 experimental data in the combinational table is

$$
\begin{aligned}
\bar{p}_{\mathrm{F}}= & (0.088391+0.630976+0.2221+0.799535+0.168144 \\
& +0.645827+0.233112+0.976240+0.061215+0.195666+0.121359 \\
& +0.217606+0.071250+0.151290+0.121646+0.272716) / 16 \\
= & 0.311067
\end{aligned}
$$

The curvature of the sum of the square variance is calculated as

$$
S S_{C}=\frac{n_{F} n_{C}\left(\bar{p}_{F}-\bar{p}_{C}\right)^{2}}{n_{F}+n_{C}}=\frac{(16)(4)(0.311067-0.250148)^{2}}{16+4}=0.011876
$$

The error of the sum of the square variance is 
Table 5

MPCI values in Cases 1, 2, and 3.

\begin{tabular}{cccc}
\hline \multirow{2}{*}{ Runs } & Case 1 & Case 2 & Case 3 \\
\cline { 2 - 4 } & Inverse of inlet temperature & Inverse of outlet temperature & MPCI \\
\hline 1 & 0.014554 & 0.016021 & 0.088391 \\
2 & 0.019900 & 0.022002 & 0.630976 \\
3 & 0.015284 & 0.016748 & 0.222100 \\
4 & 0.023607 & 0.023895 & 0.799535 \\
5 & 0.014415 & 0.015835 & 0.168144 \\
6 & 0.019759 & 0.022784 & 0.645827 \\
7 & 0.015024 & 0.017572 & 0.233112 \\
8 & 0.024492 & 0.026976 & 0.976240 \\
9 & 0.013390 & 0.014531 & 0.061215 \\
10 & 0.014868 & 0.016184 & 0.195666 \\
11 & 0.013945 & 0.015078 & 0.121359 \\
12 & 0.015249 & 0.016815 & 0.217606 \\
13 & 0.013490 & 0.014276 & 0.071250 \\
14 & 0.014217 & 0.015574 & 0.151290 \\
15 & 0.013970 & 0.015042 & 0.121646 \\
16 & 0.016041 & 0.018212 & 0.272716 \\
\hline 17 & 0.016003 & 0.017790 & 0.261394 \\
18 & 0.015274 & 0.017117 & 0.229883 \\
19 & 0.015691 & 0.017428 & 0.246822 \\
20 & 0.015957 & 0.017883 & 0.262494 \\
\hline
\end{tabular}

$$
S S_{E}=\sum_{i=1}^{n_{C}}\left(p_{i}-\bar{p}_{C}\right)^{2}=(0.261394-0.250148)^{2}+\ldots+(0.262494-0.250148)^{2}=0.000701,
$$

where

$n_{F}$ : number of experimental runs in combinational table.

$n_{C}:$ number of experimental runs in central-point experiments.

The $\mathrm{F}$ statistic is derived as

$$
F=\frac{S S_{C} / 1}{S S_{E} /\left(n_{C}-1\right)}=\frac{0.011876}{\frac{0.000701}{4-1}}=50.85 .
$$

The regressive model is derived as

$$
\begin{aligned}
p= & 0.298883+0.175165 r_{1}+0.059472 r_{2}+0.018961 r_{3}-0.15947 s_{1} \\
& -0.00759 s_{2}+0.02082 r_{1} r_{2}+0.006352 r_{1} r_{3}+0.011428 r_{2} r_{3}-0.11744 r_{1} s_{1} \\
& -0.02773 r_{2} s_{1}-0.01633 r_{3} s_{1}-0.00021 r_{1} s_{2}-0.00627 r_{2} s_{2}-0.01672 r_{3} s_{2} .
\end{aligned}
$$

The mean response surface is derived as

$$
\begin{aligned}
E_{S}(p(r, s))= & b_{0}+r^{\prime} \boldsymbol{b}+r^{\prime} \boldsymbol{B} r \\
& =0.298883+0.175165 r_{\square}+0.059472 r+0.018961 r \\
& +0.02082 r_{1} r_{2}+0.006325 r_{1} r_{3}+0.011428 r_{2} r_{3} .
\end{aligned}
$$


The variance response surface is formulated as

$$
\begin{aligned}
& \operatorname{Var}_{s}(p(r, s))=\sum\left(\frac{\partial p}{\partial s_{i}}\right)^{2} \sigma_{s i}^{2}=\left(\frac{\partial p}{\partial s_{1}}\right)^{2} \sigma_{s 1}^{2}+\left(\frac{\partial p}{\partial_{s 2}}\right)^{2} \sigma_{s 2}^{2} \\
& \frac{\partial p}{\partial s_{1}}=-0.117439 r_{1}-0.027734 r_{2}-0.016329 r_{3}-0.159474 \\
& \frac{\partial p}{\partial s_{2}}=-0.000211 r_{1}-0.006274 r_{2}-0.016717 r_{3}+0.0075851
\end{aligned}
$$

Assuming that the standard deviations of $s_{1}, s_{2}$ are $\sigma_{s_{1}}=1, \sigma_{s_{2}}=1$, then the variance response surface is derived as

$$
\begin{aligned}
\operatorname{Var}_{s}(p(r, s))= & \left(-0.117439 r_{1}-0.027734 r_{2}-0.016329 r_{3}-0.159474\right)^{2}(1)^{2} \\
& +\left(-0.000211 r_{1}-0.006274 r_{2}-0.016717 r_{3}-0.007585\right)^{2}(1)^{2} \\
& =0.037460 r_{1}+0.008941 r_{2}+0.005462 r_{3}+0.006517 r_{1} r_{2} \\
& +0.003842 r_{1} r_{3}+0.001115 r_{2} r_{3}+0.013792 r_{1}^{2}+0.000809 r_{2}^{2} \\
& +0.000546 r_{3}^{2}+0.025489 .
\end{aligned}
$$

The mean response surface is plotted in Fig. 23. The associated contour plot is shown in Fig. 24. The variance response surface is plotted in Fig. 25. The associated contour plot is shown in Fig. 26.

The overall optimization problem is formulated as

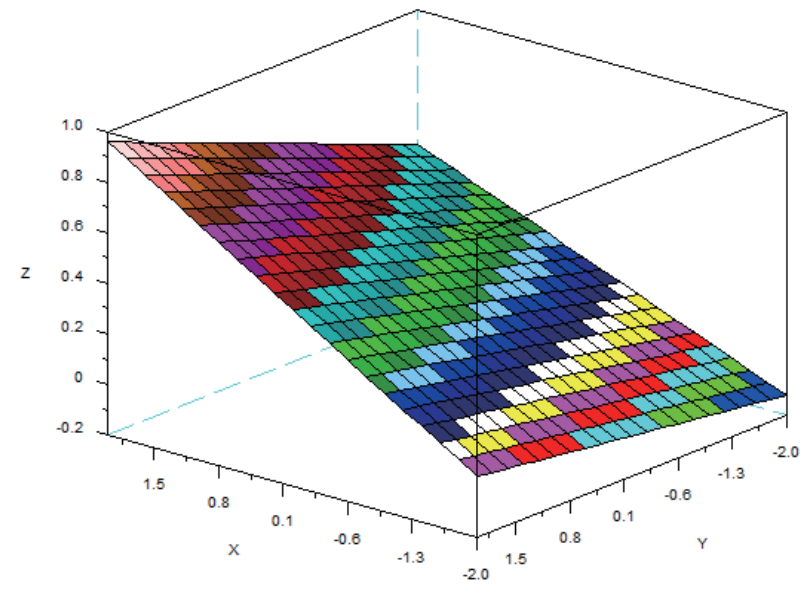

Fig. 23. (Color online) Three-dimensional plot of mean response surface.

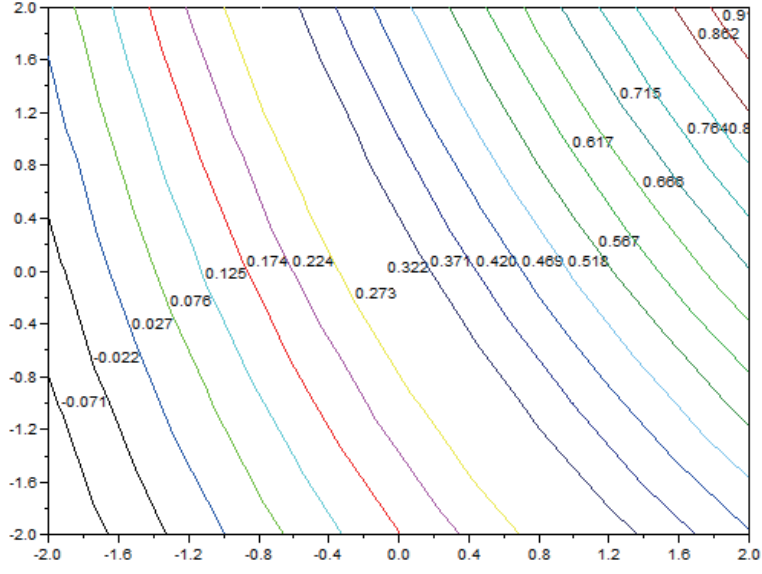

Fig. 24. (Color online) Contour plot of mean response surface. 


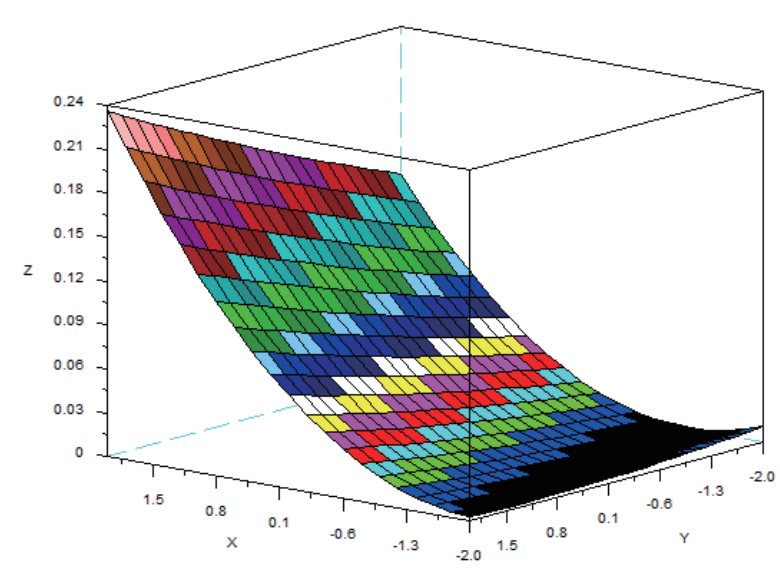

Fig. 25. (Color online) Three-dimensional plot of variance response surface.

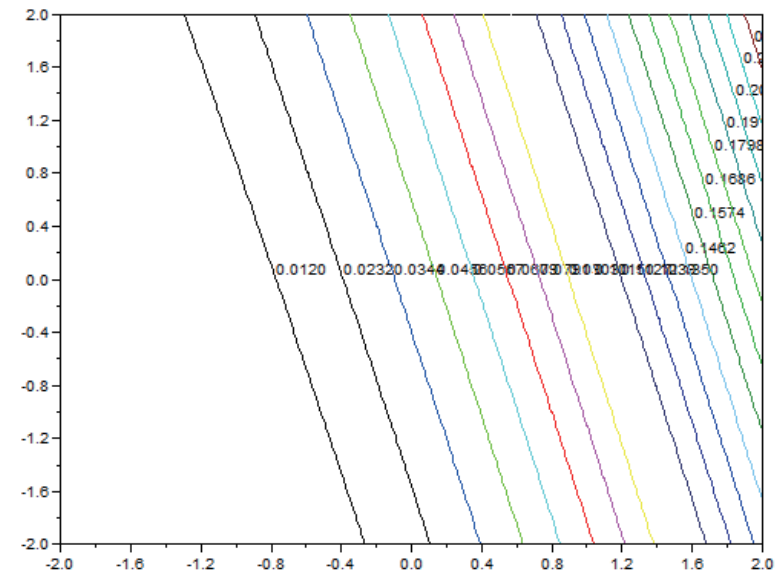

Fig. 26. (Color online) Contour plot of variance response surface.

$$
\begin{aligned}
\operatorname{Min}_{s}(p(r, s))= & 0.348641+0.105007 r_{\square}+0.033469 r+0.009046 r \\
& +0.026088 r_{1} r_{2}+0.003792 r_{1} r_{3}+0.005856 r_{2} r_{3},
\end{aligned}
$$

which is subject to

$$
\begin{aligned}
\operatorname{Var}_{s}(p(r, s))= & 0.016763 r_{1}+0.004302 r_{2}+0.000038 r_{3} \\
& +0.003606 r_{1} r_{2}+0.000201 r_{1} r_{3}+0.000162 r_{2} r_{3} \\
& +0.006928 r_{1}^{2}+0.000485 r_{2}^{2}+0.000189 r_{3}^{2}+0.010196 \\
\leq & 100 .
\end{aligned}
$$

The constraints of the variables are

$$
-2.0 \leq r_{1} \leq 2.0,-2.0 \leq r_{2} \leq 2.0,-2.0 \leq r_{3} \leq 2.0
$$

Therefore, the optimization problem is completely formulated and the statistical model is built up. In the following, the optimization process by orthogonal particle swarm optimization to derive the optimal solution is discussed.

\section{Optimal Solution of Statistical Model by Orthogonal Particle Swarm Optimization}

\subsection{OPSO derivation}

Particle swarm optimization emulates the group dynamic behavior of animals. ${ }^{(21-24)}$ Each particle in a group is affected not only by itself but also by the overall group. Position and velocity vectors are defined for each particle. The search method combines the contribution of 
the individual particle with the contribution of the group. For a particle modeled as a point in a search space with $D$ dimensions, the $i$ th particle associated with the problem is defined as ${ }^{(23,24)}$

$$
X_{i d}=\left(r_{i 1}, r_{i 2}, \ldots, r_{i D}\right) \text {, }
$$

where $d=1,2, \ldots, D, i=1,2, \ldots, P S$, and $P S$ is the population size. The individual particle value and the group value associated with each particle $X_{i d}$ are respectively defined as

$$
\begin{gathered}
P_{p d}=\left(p_{p 1}, p_{p 2}, \ldots, p_{p D}\right), \\
P_{g d}=\left(p_{g 1}, p_{g 2}, \ldots, p_{g D}\right) .
\end{gathered}
$$

The speed vector used to refresh the optimization is defined as

$$
V_{i d}=\left(v_{i 1}, v_{i 2}, \ldots, v_{i D}\right) \text {. }
$$

The position and velocity vectors are updated as

$$
V_{i d}^{n+1}=V_{i d}^{n}+c_{1} \times \operatorname{rand}() \times\left(P_{p d}-X_{i d}^{n}\right)+c_{2} \times \operatorname{rand}() \times\left(P_{g d}-X_{i d}^{n}\right),
$$

where $X_{i d}^{\square+1}=X_{i d}+V_{i d}$.

\subsection{Optimal solution of statistical model}

The optimization problem is solved to obtain the optimal solution of $\left(r_{1}, r_{2}, r_{3}\right)=(+2.0000,+2.0000,+2.0000)$. The optimal mean response is derived as $E_{s}(p(r, s))=0.96037$ and the optimal variance response is derived as $\operatorname{Var}_{s}(p(r, s))=0.23351$. In other words, the mileage of filter usage is $60000 \mathrm{~km}$, the filter type is $0.9 \mathrm{kPa}$, and the inverter limited current is $1700 \mathrm{~A}$. The optimal MPCI value is 0.96037 . The optimal inverse of the inlet temperature is 0.024492 , which means that the optimal inlet temperature is $40.83{ }^{\circ} \mathrm{C}$. The optimal inverse of the outlet temperature is 0.026976 , which means that the optimal outlet temperature is $37.07^{\circ} \mathrm{C}$.

\section{Discussion}

(1) As shown in Table 6, the inlet temperature is minimized in Case 1 and the outlet temperature is minimized in Case 2. In Case 3, the inlet/outlet mixed MPCI value, which combines the minimum inlet and outlet temperatures, is minimized. Since the curvature of the statistical model is very small, a first-order model is used to describe the problem. 
Table 6

Comparison of Cases 1, 2, and 3.

\begin{tabular}{|c|c|c|c|}
\hline Item & Case 1 & Case 2 & Case 3 \\
\hline Method & RSM & RSM & Fuzzy MPCI RSM \\
\hline Objective function & Inlet temperature & Outlet temperature & Inlet/outlet mixed MPCI value \\
\hline Curvature & 12.3607 & 4.504 & 50.85 \\
\hline Solution & $\begin{array}{c}0.025144 \\
\left(39.77^{\circ} \mathrm{C}\right)\end{array}$ & $\begin{array}{c}0.025248 \\
\left(39.60^{\circ} \mathrm{C}\right)\end{array}$ & $\begin{array}{c}0.024492 \\
\left(40.83^{\circ} \mathrm{C}\right)\end{array}$ \\
\hline
\end{tabular}

(2) Cases 1 and 2 have similar solution sets. In the solution of Case 3, the outlet temperature is the lowest among the cases but the inlet temperature is not the lowest. However, the inlet temperature is still acceptable as compared with those of Cases 1 and 2.

(3) The heat sink modules and nanofilters are essential components in the traction motor drive system of high-speed trains. To ensure the safety of high-speed trains, the maintenance problem should be emphasized and studied intelligently.

\section{Conclusions}

The nanofilter-type heat sink module is a key factor of high-speed trains, which cannot be simulated by CFD software. Also, the mileage of filter usage is a factor related to the maintenance problem. It is necessary to analyze the effect of different nanofilter types and the mileage of filter usage by a design of experiments (DOE) method.

In this study, measured data were analyzed by the RSM. A statistical model was derived to reveal the relation between the inlet/outlet temperature values and three control factors. The optimal lowest temperature values were obtained to realize the practical design of heat sink modules and to ensure the safe operation of a train traction motor drive system.

The inlet temperature and outlet temperature were evaluated simultaneously using a fuzzy MPCI method, with fuzzy inference used to combine the two values into a single compact index. The mean response surface and variance response surface were derived to describe the studied problem. The inlet/outlet temperature objective functions were represented and associated with the three control factors. The three control factors practically considered in this model might be encountered in practical problems.

It is expected that the proposed statistical model can be further developed as a cloud model and uploaded onto a cloud server to provide smart cloud-based predictive maintenance for a high-speed railway system. A good design reference was successfully developed to realize an intelligent industrial maintenance system related to nanofilters and heat sink fins for a highspeed railway system using IoT and Industry 4.0.

\section{Acknowledgments}

The experimental setup employed in this study was partially supported by Tzan-Hsing Inc. 


\section{References}

1 A. Sarkar and B. Issac: Int. J. Eng. Sci. Technol. 20 (2017) 542.

2 C.-W. Han and S.-B. Jeong: J. Int. Council Electr. Eng. 6 (2016) 17.

3 M. Chen, A. Hu, B. Wang, and Y. Tang: 2010 Int. Conf. Intelligent System Design and Engineering Application, Changsha (2010) 557-560.

4 C. W. Yu and R. L. Webb: Proc. IEEE Semi-Therm Symp. (2001) 18-26.

5 T. Y. Lee: IEEE Trans. Components Packag. Technol. 23 (2000) 55.

6 C. S. Yun, P. Malberti, M. Ciappa, and W. Fichtner: IEEE Trans. Adv. Packag. 24 (2001) 401.

7 S. D. Lee, C. Hong, C. S. Yang, and K. S. Kim: IEEE 7th Int. Conf. Power (2000) 295-299.

8 K. A. Moores and Y. K. Joshi: 7th Int. Conf. Thermal and Thermomechanical Phenomena in Electronic Systems 2 (2000) 385-390.

9 J. S. Kim, W. H. Cha, K. N. Rainey, S. Lee, and S. M. You: Proc 10th Int. Conf. Phenomena in Electronics Systems, San Diego, CA (2006) 8.

10 T. E. Salem, D. Porschet, and S. B. Bayne: Semiconductor Thermal Measurement and Management Symp, IEEE (2005) 264-269.

11 J. G. Maveety and H. H, Jung: Int. Commun. Heat Mass Transfer 27 (2000) 229.

12 A. Morozumi, H. Hokazono, Y. Nishimura, Y. Ikeda, Y. Nabetani, and Y. Takahashi: Proc. 25th Int. Symp. Power Semiconductor Devices and ICs, Kanazawa (2013) 109-112.

13 K. T. Chiang: Int. Commun. Heat Mass Transfer 32 (2005) 1193.

14 Y. Cheng, G. Xu, D. Zhu, W. Zhu, and L. Luo: IEEE Trans. Components Packag. Technol. 29 (2006) 39.

15 B. Sun and Z. Wu, Proc IEEE 2nd Int. Conf. Computer Engineering and Technology (2010) 397-400.

16 P. B. S. Reddy, K. Nishina, and A. S. Babu: Int. J. Quality Reliability Manage. 15 (1998) 646.

17 H. J. Zimmermann: Fuzzy Set Theory and Its Applications (Kluwer Academic Publishers, London, UK, 1985) Chap. 2.

18 Z. L. Gaing and J. A. Chiang: Proc. IEEE Power and Energy Society General Meeting (2010) 1-7.

19 C. W. Hung and C. Y. Huang: M.S. Thesis, Optimization for Plastic Injection Molding Operations by Dual Response Surface Method and Non-linear Programming, Dept. Industrial Engineering, Tunghai University, Taiwan (1998) Chap. 2.

20 Z. Malik and K. Rashid: IEEE Trans. Magnetics 36 (2000) 241.

21 Y. Shi and R. Eberhart: Proc IEEE Int. Conf. Evolutionary Computation (1998) 69-72.

22 R. Eberhart and Y. Shi: Proc. Congr. Evolutionary Computation (2000) 84-88.

23 S. Y. Ho: IEEE Trans. Syst. Man Cybern. 38 (2008) 288.

24 B. Y. Qu, P. N. Suganthan, and S. Das: IEEE Trans. Evol. Comput. 17 (2013) 387. 